\title{
Analysis of 2 Cases of Puncture and Suction of Intrauterine Exudate Guided by Transvaginal B-Ultrasonography during Early Pregnancy
}

\author{
Chen Lin, Qicai Liu, Shuxian Chen, Mei Lian, Wenxia Huang and Yujia Guo* \\ Department of Reproductive Medicine Centre, $1^{\text {st }}$ Affiliated Hospital, Fujian Medical University, Fuzhou, 350005, China
}

Received: 畊: December 13; Published: 制: December 21, 2018

*Corresponding author: G.Y.J. Department of Reproductive Medicine Centre, $1^{\text {st }}$ Affiliated Hospital, Fujian Medical University, 20 Chazhong Road, Fuzhou, 350005, China. Email: guoyujia51@163.com

Abstract

Objective and Methods: To eliminate the intrauterine exudate during early pregnancy after In Vitro Fertilization and Embryo Transfer (IVF-ET), puncture and suction of intrauterine exudate guided by vaginal B-ultrasonography was analyzed. Two methods for treating intrauterine exudates were discussed.

Results: Two patients underwent puncture and suction by transvaginal B-ultrasonography for intrauterine exudate. One patient continued to pregnancy and born two baby boys and the another one aborted.

Conclusion: Puncture and suction of intrauterine exudate guided by vaginal B-ultrasonography could be a better way than intrauterine suction by transcervical canal intubation during early pregnancy.

\section{Introduction}

More attention is paid to intrauterine exudates that occurred before embryo transfer or before artificial insemination. However, there were less reports of intrauterine exudate after pregnancy and many of that were not strictly distinguished from abortion [1]. To distinguish from abortion, intrauterine exudates during early pregnancy in our center was defined as follows:

a) patient with high risk factors such as history of intrauterine exudate or leakage, hysteromyoma, adenmyosis or OHSS after ovarian stimulation,

b) patient without vaginal bleeding,

c) B-ultrasonography shows fluid. Sonolucent area in uterine cavity rather than hypoechoic sonolucent area because of cavity bleeding.

Two cases of intrauterine exudate occurred during early pregnancy after the IVF-ET in this paper and the number of intrauterine exudates developed progressively. There was a history of repeated IVF-ET failures in one case and repeated abortions in another case. To avoid embryo loss, puncture and suction of intrauterine exudate guided by vaginal B-ultrasonography was performed and permitted by the Hospital Reproductive Medical Ethics Committee and patients. The process is described as follows.

\section{Case Materials}

Case 1

A 29-year-old woman was treated for sequela of pelvic inflammatory disease and adenmyosis. She had a history of bilateral salpingectomy and underwent 4 times of IVF-ET from 2015 to 2016 in our hospital. A small amount of fluid was found in the uterine cavity on the day of embryo transfer every IVF-ET. One developed an ectopic pregnancy and the remaining 3 failed. In April 2017, the luteal phase ovarian stimulation was performed again, AMH 1.49ng/ml and 5 oocytes were obtained and there were 3 transplantable blastocysts on day 5. In July 2017, Frozen Embryo Transfer (FET) was carried out in a modified natural cycle. On the HCG day, the endometrium was $8.5 \mathrm{~mm}$ and E2 was $1448.0 \mathrm{pmol} /$ $\mathrm{ml}$. Three blastocysts (5B-C, 3B-B-, 3BB) were transferred on day 5. the endometrium was $7.4 \mathrm{~mm}$. And the echo of uterine cavity was uniform. $\beta$-HCG was $266.6 \mathrm{mIU} / \mathrm{ml}$ and the progesterone were 
$>190.8 \mathrm{nmol} / \mathrm{ml}$ after 10 days. the maximum anterior-posterior diameter (APD) of the separation of uterine cavity was $7.0 \mathrm{~mm}$. Puncture and suction by transvaginal B-ultrasonography via the fundus of uterine cavity was performed on the same day due to the great possibility of early abortion. The suction continued for 10 seconds with the negative pressure of $80 \mathrm{mmHg}$.

About $0.5 \mathrm{ml}$ of white exudate was drawn out and no embryonic structure was found in the exudates under microscopy. B-ultrasonography showed APD $1.0 \mathrm{~mm}$ after the operation. The level of $\beta$-HCG was $5333.0 \mathrm{mIU} / \mathrm{ml}$, B-ultrasonography showed APD $5.0 \mathrm{~mm}$ after 3 days. The same operation was performed again. Approximate $0.4 \mathrm{ml}$ of reddish exudates was drawn out and APD was $1.0 \mathrm{~mm}$ after the suction. After 15 days, B-ultrasonography showed intrauterine twin pregnancy and the intrauterine exudates was still present. APD was $4.5 \mathrm{~mm}$. The third same operation was performed, and approximate $0.4 \mathrm{ml}$ of reddish exudates was drawn out and APD was about $1.0 \mathrm{~mm}$ after the suction. Oral cephalosporins were given to prevent infection during all the three suctions. There was no transvaginal bleeding or fever after the operations. At 12 weeks of gestation, NT B-ultrasonography showed intrauterine twin pregnancy, central placenta previa and disappeared intrauterine exudates. The placenta previa became marginal after 20 weeks of gestation. Two healthy baby boys have been delivered.

\section{Case 2}

A 41-year-old female was treated for expected low ovarian response accompanied by hysteromyoma and endometrial polypectomy. She has a history of 2 spontaneous abortions for unknown reason. In December 2016, the luteal phase ovarian stimulation was performed, 5 oocytes were obtained, and 2 blastocysts (3B-B, 3BB) were obtained on day 5. FET was carried out in a modified natural cycle in August 2017. The endometrium was $9.0 \mathrm{~mm}$ on the HCG day. It was $9.0 \mathrm{~mm}$ and intrauterine exudate was not found on the day of transfer. Two blastocysts were transferred on day 5. Blood $\beta$-HCG was $635.6 \mathrm{mIU} / \mathrm{ml}$ and the APD of uterine cavity effusion was $2.0 \mathrm{~mm}$ after 11 days. Three days later, APD increased to $8.0 \mathrm{~mm}$. Puncture and suction by transvaginal B-ultrasonography was performed in the same way as above-mentioned. $0.7 \mathrm{ml}$ of white exudate was drawn out and the APD was $1.5 \mathrm{~mm}$ after the suction. $\beta$-HCG was $3887.0 \mathrm{mIU} / \mathrm{ml}$ and APD was $6.5 \mathrm{~mm}$ after 6 days. The suction was performed again. 0.5 $\mathrm{ml}$ of reddish exudate was drawn out and APD was $1.0 \mathrm{~mm}$ after the suction. B-ultrasonography showed that APD was $2.0 \mathrm{~mm}$ after 4 days and an $8 \times 6 \times 7 \mathrm{~mm}$ intrauterine gestational sac was detected. Vaginal bleeding occurred after 7 days. B-ultrasonography showed that the gestational sac had been lost.

\section{Discussion}

The incidence of intrauterine exudate or leakage before embryo transfer is $4.2 \%$ to $11.1 \%$ [2]. It is common in patients with tubal effusion, PCOS, OHSS, hysteromyoma, adenmyosis, intrauterine infection, etc [3]. Its occurrence is mostly related to hyper-physiological hormone level, fallopian tube factors, immunological abnormality and relevant changes of the intrauterine microenvironment [4]. The intrauterine exudates after IVF-ET during early pregnancy is rarely reported and is difficult to distinguish it from intrauterine bleeding because of abortion. The reason for the occurrence is like the above. And the expectant or conservative treatment for intrauterine exudates is generally taken. The intrauterine exudates is usually assessed by APD. The expectant or conservative treatment is mostly used in patients who produce intrauterine exudates in a short time. In our center, patients with with APD $<3.0 \mathrm{~mm}$ were treated appropriately with glucocorticoids, cephalosporins, and baotailing tablets (a traditional Chinese medicine).

The intrauterine exudates can disappear within 2 weeks in the majority of patients. Several studies have suggested that when excessive intrauterine exudate exists, that is, APD $\geq 3.5 \mathrm{~mm}$, the exudate will hardly disappear in a short time, and it will have a negative impact on the clinical outcome of IVF-ET, especially in patients with tubal infertility or with persistent intrauterine exudate on the day of embryo transfer. Embryo transfer should be cancelled in this situation [5]. Intrauterine exudates occurred during early pregnancy after FET in both cases and no treatment was reported when the intrauterine exudates was persistent and APD was $>3.0 \mathrm{~mm}$. Because the patients' estradiol was $<2000$ pmol/L on the HCG day, the intrauterine exudates may be related to adenomyosis in the first case, and the another to hysteromyoma companied with polypoid hyperplasia of uterine cavity in the second case. APD was $>3.0 \mathrm{~mm}$ during the early pregnancy and persistent and there had been a history of multiple failures of IVFET and a history of recurrent abortion which meant high probability of abortion during early pregnancy. APD value did not reduce after conservative treatment. Therefore, it is decided to take further treatment to keep pregnancy. Intrauterine suction by transcervical cannulation is usually used to eliminate exudate before embryo transfer [6].

It was not reported after embryo transfer and the reason is that it is easy to damage the newly implanted embryo because it is difficult to control the negative pressure and area of suction. The puncture and suction guided by transvaginal B-ultrasonography was adopted to minimize the damage to the embryo after discussion.

The reasons are as follows:

a) The area of suction by puncture is easier to be controlled and more limited than that by transcervical canal cannulation,

b) The negative pressure and the time of suction is constant and can be controlled in a safer range;

c) We have the similar experience from multifetal pregnancy reduction by transvaginal B-ultrasonography. The puncture damage to uterine can be ignored.

d) The probability of stabbing the newly implanted embryo is low after selecting the direction of the puncture.

The exudates were significantly reduced after 2-3 times of puncture and suction in the 2 cases of intrauterine exudates. 
Two babies have been delivered in one case, and miscarriage occurred in another case. The analysis of above two cases means that this method is more feasible and safer than intrauterine suction by transcervical canal cannulation for the treatment of massive intrauterine exudate during early pregnancy. It is an innovative treatment of intrauterine exudates. Of course, there is something to be improved. For viscous intrauterine exudates, it could be considered to inject a small amount of $\alpha$-chymotrypsin to decompose and dilute the intrauterine exudates, in order to facilitate the suction.

\section{Acknowledgment}

This work was supported by Joint Fund for Program of Science innovation of Fujian Province, China (no.2016Y9011). These funding sources played key supportive role for sample collection.

\section{References}

1. Tonni G, Azzoni D, Ventura A, De Felice C, Marinelli M, et al. (2009) Early detection $(9+6$ weeks) of cardiac failure in a fetus diagnosed as Turner

ISSN: 2574-1241

DOI: 10.26717/BJSTR.2018.12.002260

Yujia Guo. Biomed J Sci \& Tech Res

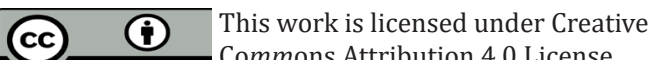

Submission Link: https://biomedres.us/submit-manuscript.php syndrome by 2D transvaginal ultrasound-guided coelocentesis. J Clin Ultrasound 37(5): 302-304.

2. He JJ, Li AH, Zhang XH (2014) Research status of the mechanism of uterine cavity effusion during in vitro fertilization and embryo transfer. Chinese journal of reproductive health 25: 483-485.

3. He RH, Zhu XM (2011) How to deal with fluid in the endometrial cavity during assisted reproductive techniques. Curr Opin Obstet Gynecol 23(3): 190-194

4. Squires EL (1996) Use of transvaginal ultrasound-guided puncture for elimination of equine pregnancies. Vet Clin North Am Equine Pract 12(1): 161-168.

5. Koskas M, Nizard J, Salomon LJ, Ville Y (2008) Abdominal and pelvic ultrasound findings within 24 hours following uneventful Cesarean section. Ultrasound Obstet Gynecol 32(4): 520-526.

6. Baradwan S, Khan F, Al Jaroudi D (2018) Successful management of a spontaneous viable monochorionic diamniotic twin pregnancy on cesarean scar with systemic methotrexate: A case report. Medicine (Baltimore) 97(37): e12343.

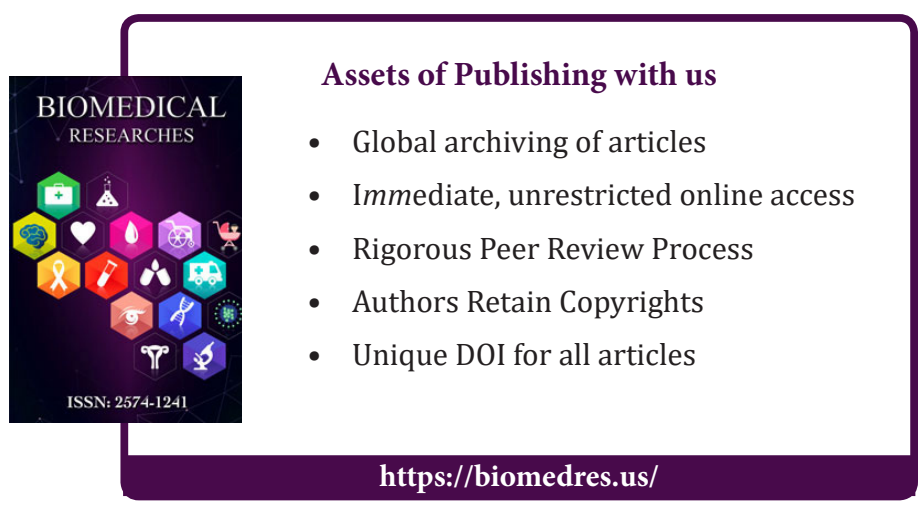

